\title{
Zona de viragem
}

Os indicadores corados são substâncias assim designadas pelo facto de, pela sua cor, darem indicações ao observador sobre as espécies químicas que existem ou predominam num sistema material. Quando ocorre uma reacção química há alteração de concentrações das espécies presentes: os reagentes dão origem total ou parcialmente aos produtos de reacção. Em situação de equilíbrio químico há coexistência de reagentes e produtos, uns e outros em maior ou menor quantidade, consoante a extensão do equilíbrio, i.e., a sua maior ou menor deslocação no sentido directo ou inverso da reacção. Estas afirmações são válidas, seja qual for o tipo de reacção que ocorre, precipitação, ácido-base, complexação, ou redox; os indicadores são escolhidos em conformidade e geralmente são espécies que intervêm em reacções do mesmo tipo que a reacção principal, mas menos extensas. O indicador e a espécie a analisar competem por uma mesma espécie química; ex: na titulação de $\mathrm{Cl}^{-} \mathrm{com}$ $\mathrm{AgNO}_{3}$, usando $\mathrm{K}_{2} \mathrm{CrO}_{4}$ como indicador, o ião $\mathrm{CrO}_{4}{ }^{2-}$ compete com $\mathrm{Cl}^{-}$pelo ião $\mathrm{Ag}^{+}$, formando o precipitado amarelo alaranjado de $\mathrm{Ag}_{2} \mathrm{CrO}_{4}$ (mais solúvel) depois da formação do precipitado branco de $\mathrm{AgCl}$ (menos solúvel). Exemplo para as reacções de complexação é o indicador Negro de Eriocrómio T, e para as reacções redox é a ferroína. Mas, na grande maioria dos casos, é no contexto das titulações ácido-base que a questão dos indicadores corados é explorada. Um indicador ácido-base, Ind, é um(a) ácido (base) fraco(a) com

*CECUL - Departamento de Química e Bioquímica, Faculdade de Ciências da Universidade de Lisboa (fcamoes@fc.ul.pt)

cor diferente da(o) respectiva(o) base (ácido) conjugada(o):

não há grande predominância de nenhuma das cores e a cor observada é

$$
\begin{aligned}
& \text { HInd }+\mathrm{H}_{2} \mathrm{O} \stackrel{\mathrm{Ka}}{\rightleftarrows} \text { Ind } \text { I }^{-}+\mathrm{H}_{3} \mathrm{O}^{+} \\
& \begin{array}{lll}
\text { Cor da } & \text { Cor da } & \mathrm{Ka}=\left[\text { Ind }^{-}\right]\left[\mathrm{H}_{3} \mathrm{O}^{+}\right] /[\mathrm{HInd}] \\
\text { forma } & \text { forma } & \\
\text { ácida } & \text { básica } &
\end{array}
\end{aligned}
$$

De acordo com o Princípio de Le Chatelier, alterações do $\mathrm{pH}$ do meio provocam deslocação do equilíbrio de ionização do indicador. Em meios de elevada acidez (i.e. baixo $\mathrm{pH}$ e abundância de $\mathrm{H}_{3} \mathrm{O}^{+}$) predomina a forma ácida do indicador, HInd, e o observador vê a cor respectiva; para elevada alcalinidade (relativa deficiência de $\mathrm{H}_{3} \mathrm{O}^{+}$, logo abundância de $\mathrm{OH}^{-}$), i.e. $\mathrm{pH}$ mais elevado, predomina a forma básica, Ind- Algumas substâncias têm mais que duas formas com cores diferentes, podendo funcionar como indicadores ácido-base em zonas de $\mathrm{pH}$ diferentes. Como exemplo tomese o azul de timol, com três formas coradas, uma forma ácida vermelha, outra forma anfiprótica intermédia amarela, e a forma básica azul, figura 1 . a cor mistura de ambas as cores, da forma ácida e da forma básica. Por substituição dos valores extremos do intervalo na equação da constante de acidez do indicador, verifica-se que a gama de valores de $\mathrm{pH}$ que garante este intervalo de concentrações das espécies ácido e base conjugados do indicador, é $\left(\mathrm{pK}_{\mathrm{a}}-1 \leq \mathrm{pH} \leq \mathrm{pK}_{\mathrm{a}}+1\right)$. Este intervalo de $\mathrm{pH}$ é conhecido como Zona (ou Intervalo) de Viragem (ZV) do indicador. A sensibilidade dos observadores não é a mesma para todas as cores, nem a mesma de observador para observador, por isso, esta gama de razões de concentrações, correspondendo a $\mathrm{pH} \approx \mathrm{pK}_{\mathrm{a}}$ \pm 1 , é um intervalo de $\mathrm{pH}$ de cerca de duas unidades:
Para o azul de timol, aumentando o pH do meio, a cor irá progredindo de vermelho para amarelo passando por laranja e depois para azul passando por verde, figura 2.

Para condições de pH em que duas formas estejam em concentrações aproximadamente iguais $\left(0,1 \leq[\mathrm{HInd}] /\left[\mathrm{Ind}^{-}\right] \leq 10\right)$,
As figuras de cor apresentadas, figuras 2 a 6 , podem ser complementadas com os correspondentes espectros de absorção de radiação visível, reforçando a explicação do fenómeno. Ao progredir na escala de $\mathrm{pH}$, aumenta o pico de absorção (ao respectivo comprimento de onda) da espécie cuja concentração aumenta, descendo o da que diminui 
(ao seu comprimento de onda característico).

Face ao que acima se explicou, torna-se evidente a razão pela qual há que proceder à escolha do indicador apropriado, $\mathrm{pK}_{a}$ (Ind), para indicar pontos de equivalência, $\mathrm{pH}$, de curvas de titulação, isto é com, $\mathrm{pK}_{\mathrm{a}}(\mathrm{Ind}) \approx \mathrm{pH}$. Para ser útil como indicador, minimizando o erro da titulação (diferença de volume de titulante adicionado, entre o valor teoricamente previsível, Ponto de Equivalência, e o valor usado até viragem do indicador, Ponto Final), o centro da zona de viragem do indicador seleccionado deve coincidir o mais posível com o pH do ponto de equivalência; dos indicadores apresentados como exemplos a escolha recairia como segue:

i) Titulação de ácido clorídrico, $\mathrm{HCl}$, com hidróxido de sódio, $\mathrm{NaOH}$; $\mathrm{pH}$ (ponto de equivalência $)=7$, indicador sugerido: tintura de tornesol, $\mathrm{pK}_{\mathrm{a}}(\mathrm{Ind})=6,4$;

ii) Titulação de hidróxido de sódio, $\mathrm{NaOH}$, com ácido clorídrico, $\mathrm{HCl} ; \mathrm{pH}$ (ponto de equivalência $)=7$, indicador sugerido: tintura de tornesol, $\mathrm{pK}_{\mathrm{a}}(\operatorname{lnd})=$ 6,4

iii) Titulação de ácido acético, $\mathrm{CH}_{3} \mathrm{COOH}$ com hidróxido de sódio, $\mathrm{NaOH} ; \mathrm{pH}$ (ponto de equivalência) $=9,2$, indicador sugerido: azul de timol, $\mathrm{pK}_{\mathrm{a}}(\mathrm{Ind})=8,9$,

iv) Titulação de amoníaco, $\mathrm{NH}_{3}$, com ácido clorídrico, $\mathrm{HCl}$; $\mathrm{pH}$ (ponto de equivalência) $=4,8$, indicador sugerido: alaranjado de metilo, $\mathrm{pK}_{\mathrm{a}}(\mathrm{Ind})=3,7$;

v) Titulação de ácido fosfórico, $\mathrm{H}_{3} \mathrm{PO}_{4}$, (ou de mistura de ácidos fortes e fracos) com hidróxido de sódio, $\mathrm{NaOH}$; a) $1 .^{\circ}$ Ponto de Equivalência, indicador sugerido: alaranjado de metilo; b) 2. ${ }^{\circ}$ Ponto de Equivalência, indicador sugerido: azul de timol;

vi) Titulação de carbonato de sódio, $\mathrm{Na}_{2} \mathrm{CO}_{3}$, (ou de mistura de bases fortes e fracas) com ácido clorídrico, $\mathrm{HCl}$; a) $1 .{ }^{\circ}$ Ponto de Equivalência, indicador sugerido: azul de timol; b) 2. ${ }^{\circ}$ Ponto de Equivalência, indicador sugerido: alaranjado de metilo.
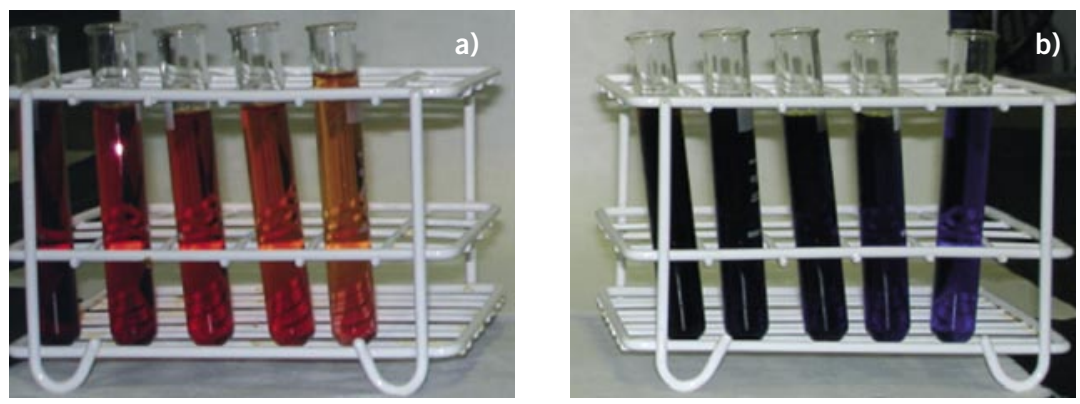

Figura 1 Solução de azul de timol em diferentes graus de diluição em água; a) com adição de HCl (aq); b) com adição de $\mathrm{KOH}$ (aq)

Figura 2 Piano de cores da solução de azul de timol, $p K a 1$ (Ind) = 1,2; pKa2(Ind) = 8,9 (Vermelho; ZV 1,2-2,8/laranja; Amarelo; ZV 8,0-9,6/Verde; Azul) a que foi adicionado: a) 0,1 M HCl; b) tampão $\mathrm{pH}=4$; c) tampão $\mathrm{pH}=7$; d) tampão $\mathrm{pH}=10$ (Para visualizar a cor do intervalo de viragem foram adicionadas algumas gotas de 0,1 M HCl, a fim de baixar o pH); e) 0,1 M KOH.

Figura 3 Violeta de metilo, $p \mathrm{Ka}($ Ind $)=0,8$ (Amarelo; ZV 0,0-1,6/Verde; Violeta); adição de 5 gotas de: a) $\mathrm{HCl}$ concentrado; b) 0,1 M $\mathrm{HCl}$ (Para visualizar a cor do intervalo de viragem foram adicionadas algumas gotas de solução comercial de $\mathrm{HCl}, 12 \mathrm{~mol} \mathrm{dm^{-3 }}$, a fim de baixar o $p H$ a valores $p H \leq 0)$; c) tampão $p \mathrm{H}=4$; d) tampão $\mathrm{pH}=7$; e) tampão $\mathrm{pH}=10$; f) $0,1 \mathrm{M} \mathrm{KOH}$.

Figura 4 Alaranjado de metilo, $p K a($ Ind $)=3,7$ (Vermelho; ZV 3,1-4,4/Laranja; Amarelo); adição de5 gotas de: a) 0,1 M HCl; b) tampão $p \mathrm{H}=4$; c) tampão $\mathrm{pH}=7$; d) tampão $\mathrm{pH}=10$; e) $0,1 \mathrm{M} \mathrm{KOH}$.

Figura 5 Azul de tornesol, $p K a($ Ind $)=6,4$ (Vermelho; ZV 5,0-8,0/Violeta; Azul); adição de 5 gotas de: a) 0,1 $\mathrm{M} \mathrm{HCl}$; b) tampão $\mathrm{pH}=4$; c) tampão $\mathrm{pH}=7$; d) tampão $p \mathrm{H}=10$; e) 0,1 M $\mathrm{KOH}$.

Figura 6 Amarelo de Alizarina,

pKa(Ind)=11 (Amarelo; ZV 10,1-12,0/Laranja; Vermelho); adição de 5 gotas de: a) 0,1 $\mathrm{M} \mathrm{HCl}$; b) tampão $\mathrm{pH}=4$; c) tampão $\mathrm{pH}=7$; d) tampão $p H=10$; e) 0,1 M KOH.
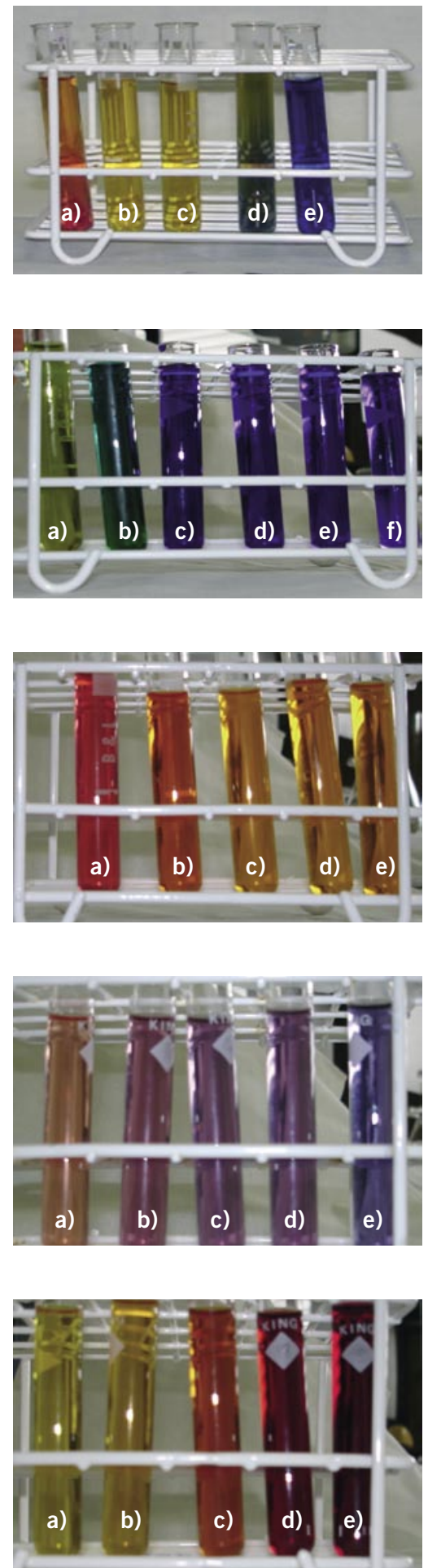